\title{
On the Simulation of the Interception of Lightning Dart Leaders
}

\author{
Mengni Long \\ Department of Electromagnetic \\ Engineering \\ School of Electrical Engineering, \\ KTH Royal Institute of Technology \\ Stockholm, Sweden \\ mengnil@kth.se
}

\author{
Marley Becerra Garcia \\ Department of Electromagnetic \\ Engineering \\ School of Electrical Engineering, \\ KTH Royal Institute of Technology \\ Stockholm, Sweden \\ marley@kth.se
}

\author{
Rajeev Thottappillil \\ Department of Electromagnetic \\ Engineering
}

School of Electrical Engineering, KTH Royal Institute of Technology

Stockholm, Sweden

rajeev@kth.se

\begin{abstract}
This paper presents the numerical evaluation of the propagation of positive upward connecting leaders under the influence of lightning dart leaders. The simulation is performed with the self-consistent leader inception and propagation model SLIM-. An analytical expression is derived for calculating the charge per unit length required to thermalize a new upward leader segment. The simulation is validated with two dart leader attachment events in a lightning triggering experiment reported in the literature. Good agreement between the estimations and the measurements of dart leader interception in length, duration and velocity of upward leader propagation has been found. Further analysis is carried out on dart lightning leader interception.
\end{abstract}

Keywords-dart leader; upward connecting leader; rocket triggered lightning

\section{INTRODUCTION}

When a lightning downward leader descends to hundreds or tens meters above the ground, one or several positive connecting leader discharges initiate from grounded objects and propagate upwards. Once one of the connecting leaders attaches to the downward leader successfully, the lightning flash would strike to the point on the grounded object where this connecting leader was initiated. This process is called lightning attachment.

Leader propagation models are an effective method to investigate downward stepped leader attachment, but they are rarely used for analysis of interception of dart leaders in subsequent strokes. It is known that the properties of lightning subsequent strokes such as $50 \%$ probability return stroke peak current and velocity and charge of the downward discharge are different than those for the first stroke [1]. The variation of these properties leads to the different lightning attachment process under dart leaders compared with the generally evaluated case under downward stepped leaders. According to the records of natural lightning and rocket triggered lightning experiments [1][2][3], upward connecting leader initiation and propagation is observed in the interception of stepped leaders as well as dart leaders. However the upward leader under the descending of dart leader is (several orders of magnitude) faster than its counterpart in stepped leader interception [2][3].

This research is sponsored by CSC Chinese Scholarship Council and Swedish strategic research program StandUp for Energy.
Due to these differences, attachment of dart leaders would be different from the case of stepped leaders.

Besides, the early stage of lightning attachment directly determines the strike point and the area of lightning attractive zone of the grounded objects under downward negative lightning, which guides the design of the lightning protection. Due to the differences in dart and stepped leader attachment, a design of lightning protection only considering stepped leader attachment cannot effectively protect the grounded objects against the damage of the subsequent strokes.

Consequently, it is necessary to evaluate lightning attachment under dart leader separately from stepped leader. Since the analysis of the lightning attachment to dart leaders, has been generally ignored in the literature, this paper intents to carry out the simulation and analysis on this subject for the first time with a leader propagation model -SLIM-. The details of simulation method of dart leader interception are presented in section II. The analytical expression for the charge per unit length for thermalization is presented in section III. The validation and analysis are presented in section IV.

\section{SimUlation Method}

In order to simulate the attachment of dart leaders to grounded objects, the self-consistent leader inception and propagation model -SLIM- [4][5][6] is used.

SLIM simulates the upward connecting leader initiation and propagation from grounded objects following a chronological sequence of discharges and considering the influence of the lightning downward leader dynamically. It includes the evaluation of the first and subsequent (precursor) streamers, the unstable upward leader initiation, the stable upward leader propagation and the final jump process when both leaders connect and the lightning attachment finally completes. Among other parameters, the velocity, length and orientation of connecting leader and the position of conjunction point of downward and connecting leaders can be predicted.

During the connecting leader propagation, charges flow through the streamer filaments, concentrate in the tip of connecting leader and thermalize the transit region in front of 
leader tip. A parameter of importance in this process is the charge $q_{L}$ required to thermalize a unit length of the connecting leader. However, this parameter depends on the several factors such as the velocity, tip radius and tip electric field of the connecting leader [7]. Even though $q_{L}$ has been evaluated numerically for stepped leaders in [4], an analytical expression for $q_{L}$ is derived here. The result of simulation is compared with two dart leader interception events in lightning triggered experiment reported by Wang [3].

\section{ANALYTICAL EXPRESSION FOR THE CHARGE PER UNIT LENGTH FOR THERMALIZATION}

An analytical expression for the parameter $q_{L}$ was first developed by Gallimberti's [7]. According to his thermalization model, the charge needed to thermalize a unit length of leader segment is given by the ratio between the injected current $I_{L}$ and the leader velocity $v_{L}$ :

$$
q_{L}=\frac{I_{L}}{v_{L}}
$$

The leader velocity is then expressed as:

$$
\mathrm{v}_{\mathrm{L}}=\left(\mathrm{f}_{\mathrm{rt}}+\mathrm{f}_{\mathrm{e}}+\mathrm{f}_{\mathrm{v}}\left(\frac{\tau_{\mathrm{L}} / \tau_{\mathrm{v}}}{1+\tau_{\mathrm{L}} / \tau_{\mathrm{v}}}\right)\right) * \frac{2}{7 \mathrm{kn}_{\mathrm{h}} \Delta \mathrm{T}_{\mathrm{L}}} * \int \mathrm{JEdz}
$$

where the integral on the right side of the equation represents the energy input in the transit region, and $f_{r t}+f_{e}$ and $f_{v}$ present the fraction of this energy input directly goes into thermal and vibrational reservoirs separately. It is assumed in this paper that all the energy input first goes into vibrational reservoir and relaxes into leader thermalization after the vibrational relaxation time constant $\tau_{v}$. This means that all the energy in the transition region is assumed to be spent in vibrational excitations such that no energy thermalizes the transit region instantly. The parameters in the expression are specified as the following TABLE I.

\begin{tabular}{|c|c|c|}
\hline parameter & value & description \\
\hline$\tau_{\mathrm{L}}$ & $\Delta \mathrm{z} / \mathrm{v}_{\mathrm{L}}$ & $\begin{array}{l}\text { Time for leader tip crossing } \\
\text { the transition zone }\end{array}$ \\
\hline$\tau_{\mathrm{v}}$ & $100 \mu \mathrm{s}$ & $\begin{array}{l}\text { vibrational relaxation time } \\
\text { constant }\end{array}$ \\
\hline$\Delta \mathrm{z}$ & $0.02 \mathrm{~m}$ & length of the transition zone \\
\hline $\mathrm{n}_{\mathrm{h}}$ & $2.504 \mathrm{e} 25 / \mathrm{m}^{3}$ & Number density \\
\hline$\Delta \mathrm{T}_{\mathrm{L}}$ & $1400-291.25 \mathrm{~K}$ & $\begin{array}{l}\text { Criterion temperature } \\
\text { increment }\end{array}$ \\
\hline$\eta_{0}$ & 0.0012 & Boundary of corona glow \\
\hline
\end{tabular}

TABLE I. PARAMETERS

The electric field $E$ in the transit region is approximated by the Laplacian field in front the tip of upward leader under the influence of the dart leader. This upward leader and dart leader configuration is simplified by two parabolic surfaces with identical radius of curvature $p_{C}$. Due to this configuration, it is convenient to derive the expression for the electric field $E$ under a parabolic coordinate system $(\varphi, \eta)$.

$$
z=\frac{1}{2}\left(\varphi^{2}+\eta^{2}\right), \quad r=\varphi \eta
$$

where, $\varphi^{2}=p_{C}$ represents the leader surface.

In this manner, the electric field can be written as:

$$
E^{\prime}(\varphi)=\frac{U_{0}-U_{l t}}{2 \ln \left(\sqrt{p_{C}} / \sqrt{D}\right)} \cdot \frac{1}{\varphi^{2}}
$$

where, $U_{0}$ and $U_{l t}$ are the potential of dart leader and upward leader separately, $p_{C}$ is the radius of curvature at the tip and $D$ is the distance between the leader tips. The dart leader potential $U_{0}$ is determined according the following equation [8]:

$$
U_{0}=5.86 e 6+0.72 e 6 I_{p}-0.669 e 3 I_{p}^{2}
$$

Since equation (4) does not consider the influence of ground and the thundercloud, it needs to be corrected through a function $f$ that considers the height of leader upward tip $H$ and distance $D$ between both leaders tips. Thus, that the actual electric field $E(\varphi)$ in the configuration including ground is:

$$
E(\varphi)=f(H, D) * E^{\prime}(\varphi)
$$

Then, the current density $\mathrm{J}$ in front of the leader tip is:

$$
J_{\varphi}=\frac{I_{L}}{\pi \eta_{0}^{2} \varphi^{2}}
$$

where, $I_{L}$ is connecting leader current and $\eta=\eta_{0}$ represents the boundary of the corona glow.

By inserting (4)-(7) into (2), we get the velocity of upward leader as:

$$
\begin{aligned}
v_{L}=\left(f_{r t}+f_{e}+\right. & \left.f_{v}\left(\frac{\tau_{L} / \tau_{v}}{1+\tau_{L} / \tau_{v}}\right)\right) * \frac{2}{7 k n_{h} \Delta T_{L}} \\
& * \frac{I_{L}}{2 \pi \eta_{0}^{2}} \frac{U_{0}-U_{l t}}{\ln \left(\sqrt{p_{C}} / \sqrt{D}\right)} \frac{1}{2 p_{C}} * f(H, D)
\end{aligned}
$$

where, $I_{L}$ is the current of upward leader.

Consequently, the charge needed to thermalize a leader segment per unit length can be expressed as:

$$
\begin{aligned}
q_{L}=\left(f_{r t}+f_{e}+\right. & \left.f_{v}\left(\frac{\tau_{L} / \tau_{v}}{1+\tau_{L} / \tau_{v}}\right)\right)^{-1} * \frac{7 k n_{h} \Delta T_{L}}{2} \\
& * 2 \pi \eta_{0}^{2} \frac{\ln (\sqrt{p c} / \sqrt{D})}{U_{0}-U_{l t}} 2 p c * f(H, D)^{-1}
\end{aligned}
$$




\section{VALIDATION AND ANALYSIS}

In order to validate the estimations of SLIM in response to dart leaders, two events of lightning attachment in rockettriggered lightning strokes reported by Wang [3] are considered. The attachment processes are recorded with optical images via the ALPS (with $100 \mathrm{~ns}$ time and 3.6ns spatial resolution) as well as the electric field measurements and channel-base current recording. The optical image showed that the upward connecting leader initiated from a 4 meter tall grounded metallic rod and propagated with a velocity estimated as $2 \mathrm{e} 7 \mathrm{~m} / \mathrm{s}$, while the dart leader was descending with the velocity of $4 \mathrm{e} 7 \mathrm{~m} / \mathrm{s}$. The ground electric field recording provided the electric field change due to the dart leader/ return stroke sequence $30 \mathrm{~m}$ rocket launcher. The recorded subsequent strokes had peak currents of $12 \mathrm{kA}$ and $21 \mathrm{kA}$.

In the simulation, the dart leader is assumed to initiate at the height of 2000 meters above ground and propagate straight downward above the metallic rod with a constant velocity $4 \mathrm{e} 7$ $\mathrm{m} / \mathrm{s}$. The distribution of charge density in dart leader channel is determined in such a way that the electric field change at ground level 30 meters away from the rod agrees with the measured values as showed in Fig. 1.
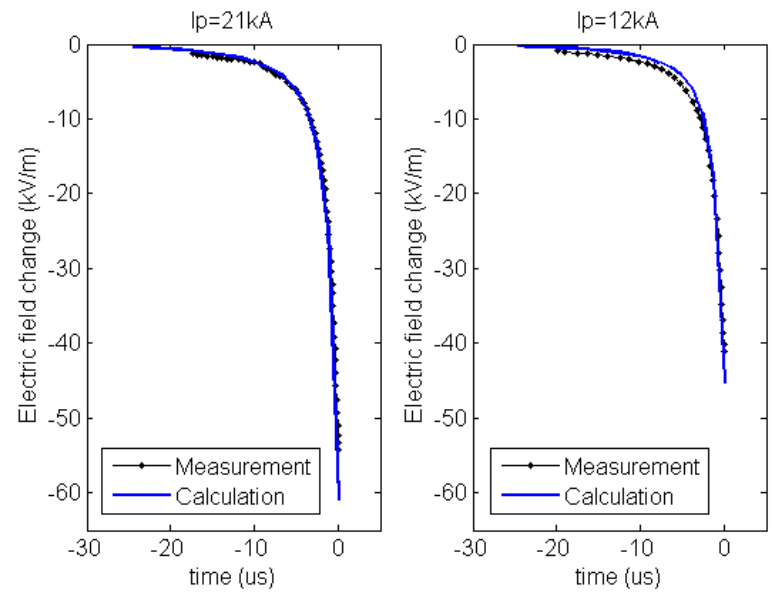

Fig. 1. Comparison between measured [4] and calculated electric fields at groud level 30 meters away from the rod for two rocket triggered lightning events.

The simulated streak images of the attachment processes of these two events are shown in in the Fig. 2. It shows the location of the tips of the dart and upward connecting leaders as well as the streamer front. As it can be seen, the first streamer is initiated when the dart leader reaches a height of $124 \mathrm{~m}$ above the ground in the $I_{p}=21 \mathrm{kA}$ case. After a dark period, the stable leader initiates when the dart leader reaches $47 \mathrm{~m}$. In the $I_{p}=12 \mathrm{kA}$ case, the first streamer is incepted when the dart leader descends at a height of $91 \mathrm{~m}$ above the ground. Then the stable connecting leader initiates when the tip of dart leader is $32 \mathrm{~m}$ in height. After this, the connecting leader propagates upward during $679 \mathrm{~ns}$ before lightning attachment taking place, reaching a total length of 6 meter in the $21 \mathrm{kA}$ case. For the $12 \mathrm{kA}$ case, the total length and duration of the upward connecting leader propagation is 4.3 meter and $453 \mathrm{~ns}$ respectively. The predicted length, velocity and duration of connecting leader propagation are in good agreement with the measurements, as summarized in TABLE II.
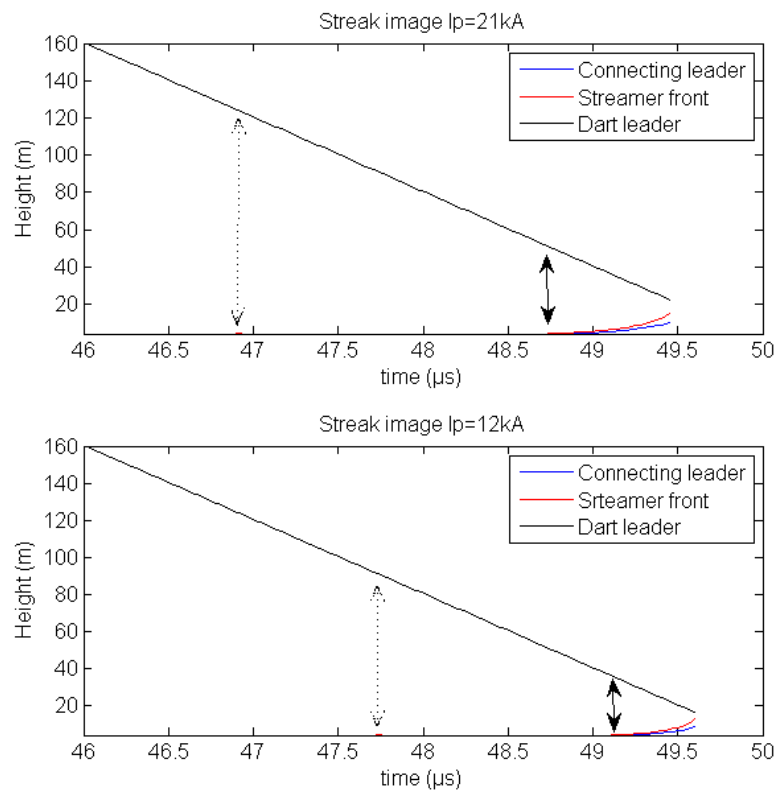

Fig. 2. Simulated streak images of leader propagation under the influence of dart leaders. The dash arrow notes the inteception of the first streamer, and the solid one notes the initiation of stable connecting leader.

TABLE II. SUMMARY OF THE UPWARD LEADER PROPAGATION PROPERTIES

\begin{tabular}{|c|l|l|l|l|}
\hline \multirow{2}{*}{$\begin{array}{c}\text { Upward } \\
\text { connect leader }\end{array}$} & \multicolumn{2}{|c|}{ Ip=21kA } & \multicolumn{2}{c|}{ Ip=12kA } \\
\cline { 2 - 5 } & Measurement & Simulation & Measurement & Simulation \\
\hline Length (m) & $7-11$ & 6 & $4-7$ & 4.3 \\
\hline Velocity (m/s) & $\sim 2 \mathrm{e} 7$ & $2.5 \mathrm{e} 7$ & $?$ & $2.7 \mathrm{e} 7$ \\
\hline Duration (ns) & $<400$ & 679 & $?$ & 453 \\
\hline
\end{tabular}




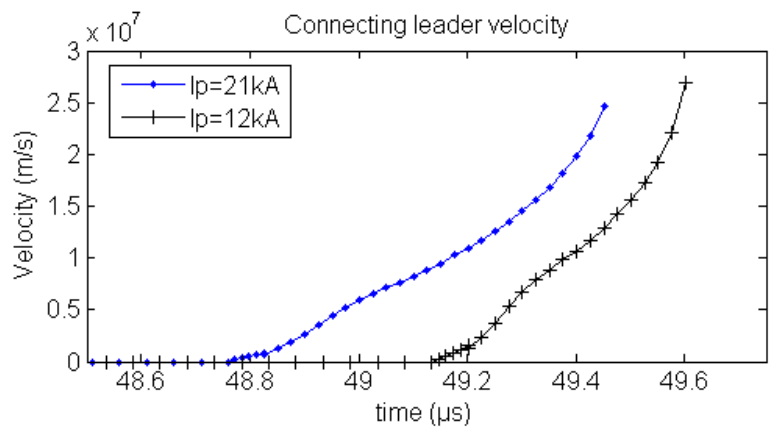

Q

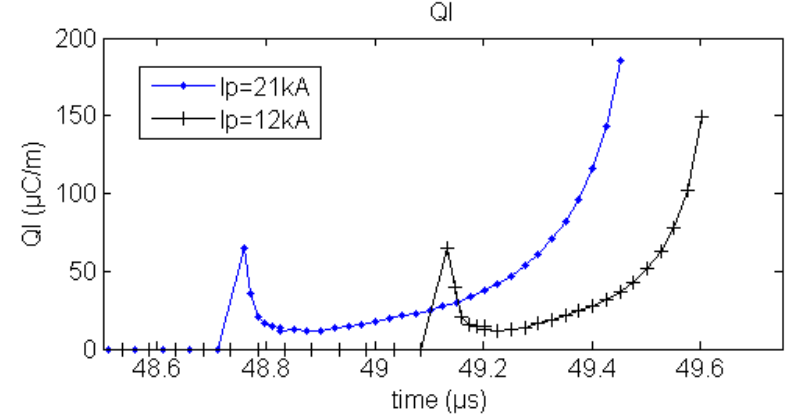

Fig. 3. Simulated upward leader velocity $v_{L}$ and thermalization charge per unit length $q_{L}$

The estimated velocity of the connecting leaders increases from $1 e 5 \mathrm{~m} / \mathrm{s}$ to about $2.5 \mathrm{e} 7 \mathrm{~m} / \mathrm{s}$ in both cases. As it can be seen in Fig. 3, the velocity of the connecting leader increases slowly during its early propagation stage due to the relatively large $q_{L}$. Then, $q_{L}$ decreases to a minimum of about $11 \mu \mathrm{C} / \mathrm{m}$ from which it starts increasing slowly keeping low values until the upward leader velocity reaches around $1 e 7 \mathrm{~m} / \mathrm{s}$. After that, $q_{L}$ shows a rapid increase that keeps the connecting leader speed increasing within a reasonable range and balances the large energy input.

The time variation of $q_{L}$ and the velocity of the connecting leader can be explained by reviewing the governing equations, rewritten as follows:

$$
\begin{gathered}
q_{L}=\frac{I_{L}}{v_{L}} \\
q_{L}=f_{v}^{-1}\left(\frac{\tau_{v}}{\Delta z} v_{L}+1\right) * \frac{7 k n_{h} \Delta T_{L}}{2} * \frac{I_{L}}{\int J E d z}
\end{gathered}
$$

Equation (10) defines $q_{L}$ as a rectangular hyperbolic function of $v_{L}$ for each connecting leader current value, as shown by the black dash lines in Fig. 4. Equation (11) represents a line in a $q_{L}-v_{L}$ plot when all the other parameters are kept constant, such that the line slope is determined by the instant ratio between the leader current and the specific energy (the energy input), showed as the blue solid lines. The intersection points (shown in red) of the two curves indicates the value of $q_{L}$ and $v_{L}$ fulfilling the two governing equations during the propagation of the connecting leader in the case of $21 k A$.

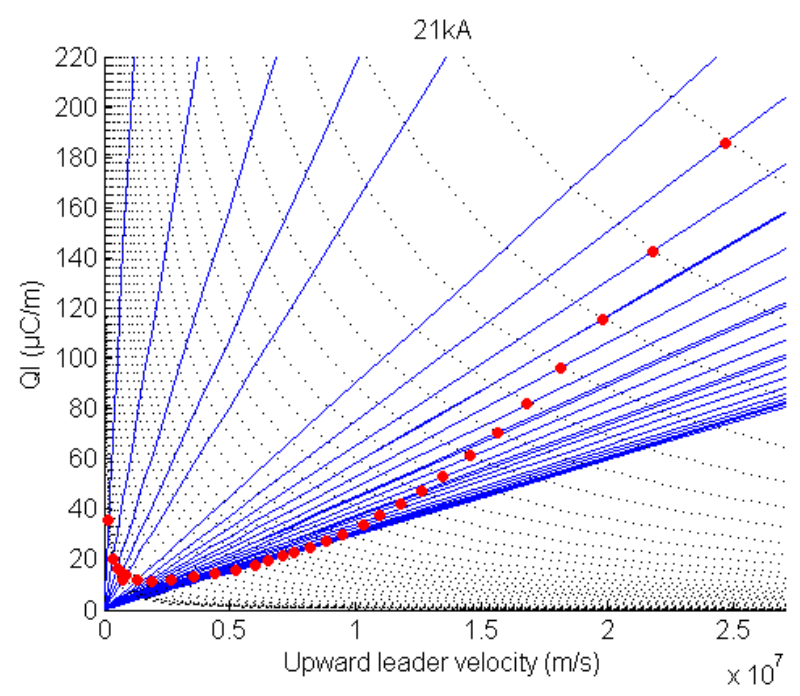

Fig. 4. Change of $q_{L}$ during the connecting leader propagation
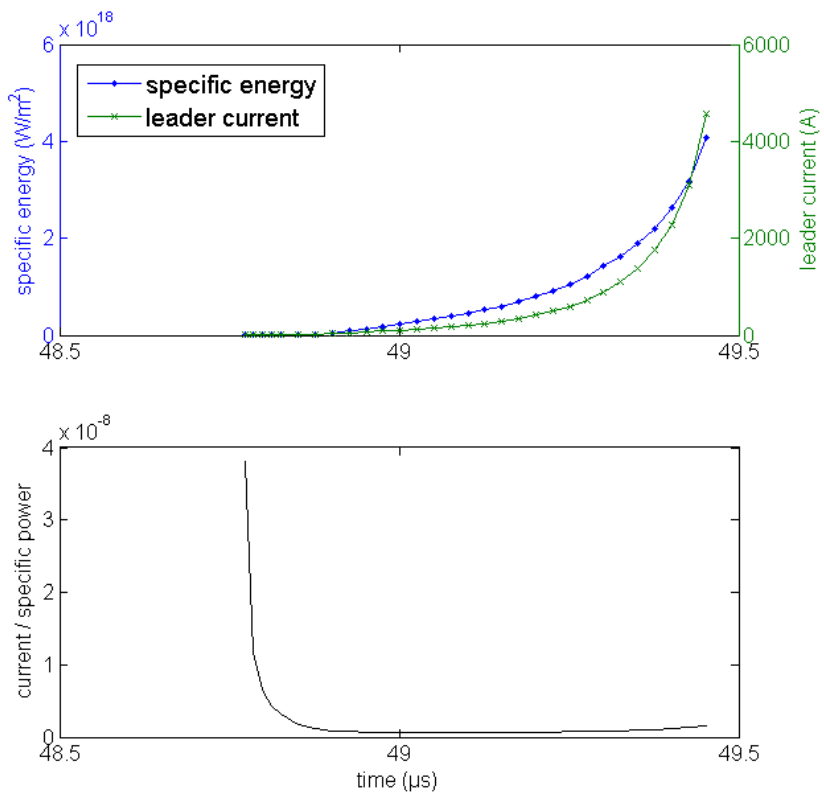

Fig. 5. Change of connecting leader current, specific energy in transit zone and connecting leader current / specific energy during the connecting leader propagation

Fig. 5a) shows the increase of the leader current and the specific energy of transit zone during the connecting leader propagation. However, the specific energy in the transit zone is very small at the early stage, which leads to very large slope of the lines in Fig. 4 (given by the ratio $\frac{I_{L}}{\int J E d z}$ ). For this reason, $q_{L}$ is relatively large in the early stage of upward leader propagation. As the upward connecting leader continues propagating towards the approaching dart leader, the specific energy of the transit zone augments at a higher rate than the leader current. This decreases the ratio $\frac{I_{L}}{\int J E d z}$ and the slope of corresponding lines. Then, the ratio between connecting leader current and the specific energy $\frac{I_{L}}{\int J E d z}$ starts increasing due to 
the fast increase of the leader current, as shown by the increase in the slope of the blue lines at high upward leader velocities in Fig. 4.

\section{CONCLUSION}

The numerical simulation of the attachment of lightning dart leaders in subsequent strokes to grounded objects is presented for first time. The analysis is performed with the self-consistent leader inception and propagation model -SLIM-. The dart leader interception is very well predicted in length, velocity and duration of upward leader propagation when an analytical expression for the charge per unit length $q_{L}$ required to thermalize a leader segment is used. The charge required for unit length upward leader thermalization $q_{L}$ is determined by connecting leader velocity, connecting leader current as well as the specific energy in the transit region. $q_{L}$ shows a relative large value at the beginning of upward leader propagation, followed a quickly decreasing and then increases with connecting leader velocity.

\section{ACKNOWLEDGMENT}

M.L greatly appreciates the scholarship support granted by the China Scholarship Council (CSC). M.B would like to acknowledge the financial support of the Swedish strategic research program StandUp for Energy.

\section{REFERENCES}

[1] Rakov, Vladimir A., and Martin A. Uman. Lightning: physics and effects. Cambridge University Press, 2007.

[2] P. Lalande, A. Bondiou-Clergerie, P. Laroche, A. Eybert-Berard, J.P Berlandis, B. Bador, A. Bonamy, M.A. Uman, V. Rakov Leader properties determined with triggered lightning techniques J. Geophys. Res, 103 (D12) (1998), p. 14109

[3] Wang, D., V. A. Rakov, M. A. Uman, N. Takagi, T. Watanabe, D. E Crawford, K. J. Rambo, G. H. Schnetzer, R. J. Fisher, and Z.-I Kawasaki (1999), Attachment process in rocket-triggered lightning strokes, J. Geophys. Res., 104(D2), 2143-2150,

[4] Becerra, M.; Cooray, V.; "A self-consistent upward leader propagation model", J. Phys. D: Appl. Phys, 39, 2006, 3708-3715

[5] Becerra, M. ; Cooray, V.; "Time dependent evaluation of the lightning upward connecting leader inception" J. Phys. D: Appl. Phys. 2006, 39 , pp. 4695-4702. doi:10.1088/0022-3727/39/21/029

[6] Becerra, M.; Cooray, V.; "A simplified physical model to determine the lightning upward connecting leader inception" IEEE Transactions on Power Delivery, Volume21, Issue 2, April 2006, Page(s):897 -908, ISSN: 0885-8977

[7] Gallimberti, I. 1972. The mechanism of long spark formation. J. Physique Coll. (Suppl.) 40 193-250.

[8] Vernon Cooray, An Introduction to Lightning, Springer Netherlands, 2015 . 